\section{The protein encoded by the proto-oncogene DEK changes the topology of chromatin and reduces the efficiency of DNA replication in a chromatin-specific manner}

\author{
Vassilios Alexiadis, ${ }^{1,3}$ Tanja Waldmann, ${ }^{1}$ \\ Jens Andersen, ${ }^{2}$ Matthias Mann, ${ }^{2}$ Rolf Knippers, ${ }^{1}$ \\ and Claudia Gruss ${ }^{1,4}$ \\ ${ }^{1}$ University of Konstanz, Department of Biology, 78457 \\ Konstanz, Federal Republic of Germany; ${ }^{2}$ Protein Interaction \\ Laboratory, University of Southern Denmark, DK-5230 \\ Odense M, Denmark
}

The structure of chromatin regulates the genetic activity of the underlying DNA sequence. We report here that the protein encoded by the proto-oncogene DEK, which is involved in acute myelogenous leukemia, induces alterations of the superhelical density of DNA in chromatin. The change in topology is observed with chromatin but not with naked DNA and does not involve dissociation of core histones from chromatin. Moreover, these effects require histone $\mathrm{H} 2 \mathrm{~A} / \mathrm{H} 2 \mathrm{~B}$ dimers in addition to histone $\mathrm{H} 3 / \mathrm{H} 4$. We additionally tested whether the DEK protein affects DNA-utilizing processes and found that the DEK protein substantially reduces the replication efficiency of chromatin but not of naked DNA templates.

Received December 13, 1999; revised version accepted April 11,2000 .

Experimental evidence has accumulated in recent years showing that chromatin is not a static structure, but rather is involved in the regulation of many nuclear processes such as transcription and replication (Felsenfeld 1996; Kingston et al. 1996; Peterson 1996; Svaren and Hörz 1996; Kornberg and Lorch 1999). In the eukaryotic nucleus, DNA is packaged into chromatin with its basic repeating motif, the nucleosome, consisting of $146 \mathrm{bp}$ of DNA wrapped around a histone octamer in a left-handed superhelix (Luger et al. 1997). The structure of chromatin affects the accessibility of DNA to sequence-specific transcription factors and to DNA-dependent enzymes such as RNA and DNA polymerases. Chromatin structure can be modulated by different factors. It has been shown, for instance, that the acetylation state of the core histones is a critical determinant of transcriptional activity (Grunstein 1997; Struhl 1998). In addition, mobi-

[Key Words: Chromatin structure; DEK; DNA topology; leukemogenesis] ${ }^{3}$ Present address: University of California, San Diego, Department of Biology, La Jolla, California 92093-0347 USA.

${ }^{4}$ Corresponding author.

E-MAIL Claudia.Gruss@uni-konstanz.de; FAX 497531884036. lization of the nucleosomes can be achieved by ATPdependent chromatin remodeling factors such as the SWI/SNF and RSC complexes from yeast (Peterson and Tamkum 1995; Cairns et al. 1996), the NURF (Tsukiyama and Wu 1995), CHRAC (Varga-Weisz et al. 1997) and ACF (Ito et al. 1997) complexes from Drosophila, and related activities in human cells (Wang et al. 1996; LeRoy et al. 1998; Tong et al. 1998; Xue et al. 1998).

On the other hand, large regions of the genome can be kept transcriptionally inert by silencing mechanisms that restrict the access of factors to their target sequences (Pirrotta 1997, 1998; Ogbourne and Antalis 1998; Wallrath 1998). Factors that are involved in chromatin repression include the SIR (silent information regulator) proteins from yeast (Grunstein 1998), the heterochromatin binding protein HP1 (Wallrath 1998), and the Polycomb group (PcG) proteins from Drosophila, which are responsible for the maintenance of the inactive state of the homeotic genes (Pirrotta 1998).

We are interested in the influence of chromatin structure on chromatin replication (Alexiadis et al. 1997, 1998; Halmer and Gruss 1997; Halmer et al. 1998; Vestner et al. 1998). During these studies we identified a protein that affects chromatin structure and replication in vitro. This factor was found to be the product of the DEK proto-oncogene, which is involved in acute myeloid leukemia (AML) (von Lindern et al. 1992).

\section{Results and Discussion}

Identification of an activity that changes the linking number of DNA in chromatin

We prepared nuclear extracts from HeLa cells and separated proteins according to the chromatographic scheme outlined in Figure 1A. Individual fractions were incubated in the presence of a cytosolic S100 extract with SV40 minichromosomes (Alexiadis et al. 1998). The DNA was extracted from minichromosomes and investigated by agarose gel electrophoresis (Fig. 1B). We identified an activity that causes a drastic reduction in the number of negative supercoils introduced by the wrapping of DNA around histone octamers. Closed circular DNA with a reduced number of supercoils was visible as numerous topoisomers between fully superhelical form I and relaxed form II DNA (Fig. 1B). By using two-dimensional gel electrophoresis in the presence of chloroquine (Krude and Knippers 1991), we found that the average linking number of nucleosomal SV40 DNA was changed in the presence of this activity from -25 to -12 (data not shown). Analysis of the most purified active fractions by SDS-PAGE revealed a prominent band with an apparent molecular mass of $50 \mathrm{kD}$ (Fig. 1C). The change in chromatin topology (Fig. 1B) was correlated with the amounts of the $50-\mathrm{kD}$ protein. The $50-\mathrm{kD}$ polypeptide was excised from a Coomassie-stained SDS-polyacrylamide gel, subjected to in-gel tryptic cleavage, and analyzed by nanoelectrospray mass spectrometry (Wilm et 
$\mathbf{A}$

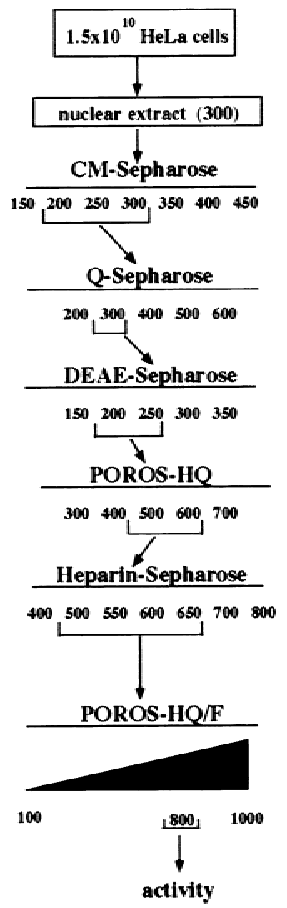

B

C

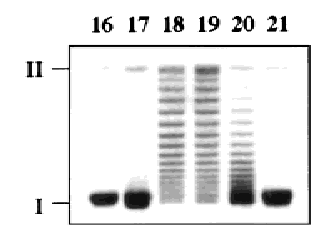

C

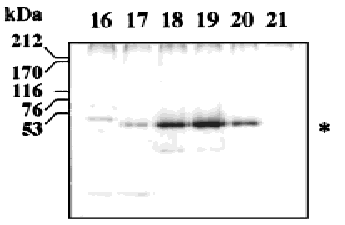

D

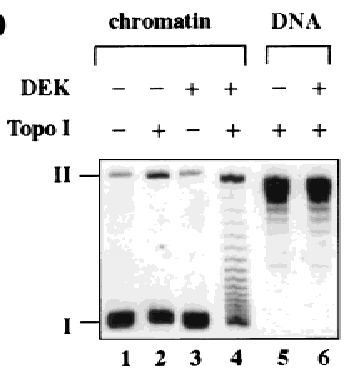

Figure 1. A $50-\mathrm{kD}$ protein reduces the superhelical density of chromatin. (A) Purification scheme of the activity. Numbers indicate $\mathrm{NaCl}$ concentration (mM). (B) SV40 chromatin was incubated with the fractions (16-21) from the POROS-HQ/F column in the presence of a cytosolic S100 replication extract. Purified DNA was investigated by agarose gel electrophoresis and ethidium bromide staining. (I) Supercoiled; (II) relaxed closed circular and nicked DNA. (C) Protein composition of the POROS-HQ/F-fractions. Proteins of the fractions (16-21) were separated by SDS-PAGE and visualized by silver staining. The position of size markers and the $50-\mathrm{kD}$ protein (asterisk) is indicated. The faster-migrating minor band on the SDS-polyacrylamide gel most likely consists of a degradation product of the $50-\mathrm{kD}$ protein, as its amount increased after prolonged incubation at $37^{\circ} \mathrm{C}$. $(D)$ Topoisomerase dependence of the reaction. SV40 chromatin (lanes 1-4) or relaxed SV40 DNA (lanes 5,6) were incubated in the absence or presence of topoisomerase I and purified DEK protein. Purified products were analyzed by agarose gel electrophoresis and visualized by ethidium bromide staining.

al. 1996 ). From the total mixture of tryptic peptides, nine were sequenced, which identified the protein as DEK.

DEK, a $43-\mathrm{kD}$ protein, was initially discovered as a fusion partner of the CAN nucleoporin in a specific subtype of AML (von Lindern et al. 1992). DEK often acts as a major immunoreactive antigen in patients with autoimmune diseases such as juvenile rheumatoid arthritis or lupus erythemathosis. However, despite these significant disease associations, the physiological function of DEK has yet to be determined.

Purified DEK changed the linking number of nucleosomal DNA in the presence of either topoisomerase I (Fig. 1D) or topoisomerase II (not shown). No additional proteins were necessary for the activity, suggesting that the cytosolic extract contributed topoisomerase activity

to the reaction shown in Figure 1B. Significantly, the linking number of relaxed naked DNA was not changed by DEK in the presence of topoisomerase I (Fig. 1D), indicating that the changes in DNA topology only occur with chromatin templates (Fig. 1D). Increasing the amounts of purified protein did not result in a complete relaxation of minichromosomal DNA, but produced a wide range of topoisomers between the negatively supercoiled base state and relaxed DNA (data not shown). At a ratio of three molecules of DEK/nucleosome (100 ng DEK/100 ng chromatin), no further change in the topoisomer ladder was observed.

To demonstrate that the change in topology of minichromosomal DNA was caused by the DEK protein, we used recombinant DEK and found that increasing amounts of GST-DEK protein (Fig. 2A) change the topology of chromatin with the same efficiency as the purified native protein preparation (Fig. 2B). In addition, we incubated chromatin with increasing amounts of NAP-1, a protein known to interact with chromatin (Chang et al. 1997). Even with the highest amount of NAP-1, we could not detect any changes in chromatin topology (data not shown), demonstrating that the effect of DEK on DNA topology is specific.

DEK is thought to be a member of a new family of site-specific DNA-binding factors involved in signal transduction and transcriptional regulation $(\mathrm{Fu}$ et al. 1997). Thus, we tested whether the DEK-induced change in chromatin topology is affected by different DNA sequences. To this end, SV40, puc18- and HK-plasmid DNA were assembled into chromatin in Drosophila S150 extracts and incubated in the presence of topoisomerase I and DEK. We found that DEK changes the linking number of all three chromatin templates to a similar extent, which indicates that the observed effect is independent of the underlying DNA sequence (data not shown).

\section{$D E K$ does not induce histone displacement}

DEK-induced changes in DNA topology could be caused by displacement of nucleosomes. To test this possibility,
A

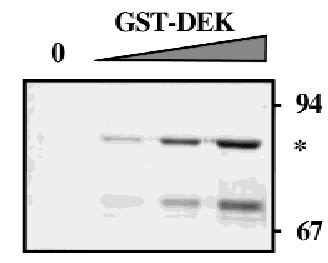

B

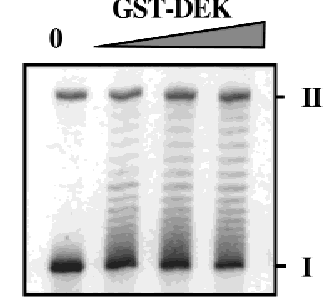

Figure 2. Recombinant GST-DEK changes the superhelical density of DNA in chromatin. (A) Increasing amounts of GSTDEK were separated by SDS-PAGE and visualized by silver staining. The positions of size markers and GST-DEK $\left({ }^{*}\right)$ are indicated. Lower band consists of a degradation product. $(B)$ DEK assay with GST-DEK. SV40 chromatin was incubated with increasing amounts of GST-DEK in the presence of topoisomerase I. Purified DNA was investigated by agarose gel electrophoresis and ethidium bromide staining. (I) Supercoiled; (II) relaxed closed circular and nicked DNA. 
we incubated chromatin with purified DEK protein and topoisomerase I and subjected the samples to glycerol gradient sedimentation (Fig. 3). Analysis by SDS-PAGE gave no evidence for a DEK-induced loss of histones, which should appear as free proteins close to the top of the gradients (Fig. 3, top). Furthermore, DEK was found in association with minichromosomes (asterisk in Fig. 3B, top, and confirmed by immunoblotting, not shown) and induced the expected change in DNA topology (Fig. $3 \mathrm{~B}$, bottom). These findings suggest that the change in linking number induced by the DEK protein is not caused by histone displacement.

\section{DEK-mediated alteration of DNA topology in chromatin requires $\mathrm{H} 2 \mathrm{~A} / \mathrm{H} 2 \mathrm{~B}$}

To investigate the components of the nucleosome that are necessary for interaction with DEK, we assembled chromatin with different histone compositions (Fig. 4AC). First, we treated SV40 minichromosomes with trypsin, which removes the unstructured amino-terminal histone tails (Ausio et al. 1989; Quintini et al. 1996; Fig. 4A, left). Second, we cross-linked core histones within the histone octamer with dimethyl suberimidate (DMS) to prevent dissociation of histones from the octamer (Thomas 1989). Cross-linked histones migrate with an apparent molecular weight of around 100,000 dalton (Fig 4B, left). Third, we deposited $\mathrm{H} 3 / \mathrm{H} 4$ tetramers onto DNA with purified $\mathrm{H} 3 / \mathrm{H} 4 / \mathrm{N} 1$ complexes (Zucker and Worcel 1990; Fig. 4C). These different substrates were incubated with and without DEK plus topoisomerase I. Agarose gel electrophoresis of extracted DNA revealed

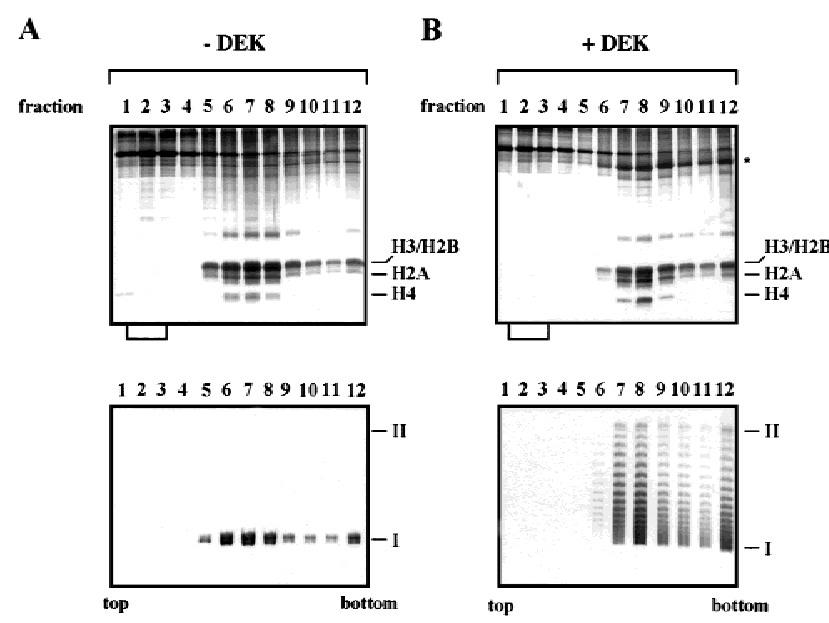

Figure 3. The DEK-induced change in linking number is not due to histone displacement. SV40 minichromosomes were incubated in the absence $(A)$ or presence $(B)$ of DEK and topoisomerase I and separated on glycerol gradients. Proteins of the gradient fractions (lanes 1-12) were analyzed by SDS-PAGE (top) and the DNA topology by agarose gel electrophoresis (bottom). The position of the core histones (H3, H2B, H2A, and H4) and supercoiled (I) and relaxed closed circular and nicked DNA (II) are indicated. Brackets below the SDS-PAGE show the position in which free histones are expected to appear. (Asterisk) Position of DEK protein. that DEK is active on chromatin substrates containing amino-terminally truncated histones (Fig. 4A, right) and cross-linked octamers (Fig. 4B, right). However, we observed that DEK was unable to change the topology of molecules containing only histone $\mathrm{H} 3 / \mathrm{H} 4$ tetramers (Fig. 4C, left). Significantly, re-addition of H2A/H2B dimers to these templates fully restored DEK activity (Fig. 4C, right). These results demonstrate that the interaction of DEK with histone $\mathrm{H} 2 \mathrm{~A} / \mathrm{H} 2 \mathrm{~B}$ dimers is necessary for the DEK-mediated change in topology of nucleosomal DNA. To provide evidence for a direct interaction of DEK with histone proteins, we performed a Far-Western blot analysis (Fig. 4D). We observed strong binding of DEK to histones H2A and H2B and a much weaker interaction with histones $\mathrm{H} 3$ and $\mathrm{H} 4$. No signal was obtained without the addition of DEK, excluding any crossreactivities of histones with our antibody. By reducing the concentration of DEK in our assay $\left(25 \mathrm{ng} / \mathrm{cm}^{2}\right.$ filter), the binding was restricted mainly to $\mathrm{H} 2 \mathrm{~A}$ and $\mathrm{H} 2 \mathrm{~B}$. The specificity of DEK for histones $\mathrm{H} 2 \mathrm{~A}$ and $\mathrm{H} 2 \mathrm{~B}$ explains the inability of DEK to change the topology of templates consisting of $\mathrm{H} 3 / \mathrm{H} 4$ tetramers only.

\section{$D E K$ reduces the replication efficiency of chromatin templates}

For genetic processes such as transcription or replication, initiation factors must gain access to their specific binding sites (Alexiadis et al. 1998). To determine whether DEK reduces the overall accessibility of chromatin, we treated SV40 minichromosomes with endonucleases. Both restriction endonuclease MboI (which cuts SV40 DNA at eight sites) and micrococcal nuclease (which attacks the linker DNA between nucleosomes) degrade DEK-treated minichromosomes with strongly reduced efficiency compared with untreated minichromosomes (not shown). More specifically, we investigated whether the DEK-mediated change in chromatin topology has an influence on chromatin replication by using DEK-treated minichromosomes that were preincubated with DEK as templates in the in vitro replication system (Fig. 5). Replication products were deproteinized and analyzed by agarose gel electrophoresis and visualized by ethidium bromide staining (Fig. 5A, chromatin) and autoradiography (Fig. 5B, chromatin). Total incorporated nucleotides were determined by TCA precipitation (Fig. 5C, chromatin). We found that the replication efficiency of chromatin templates was significantly reduced in the presence of DEK (Fig. 5B,C), concomitant with a change in the topology (Fig. 5A), demonstrating that the altered chromatin structure inhibits the access of replication factors to the DNA template. In addition, we investigated the effects of DEK on the replication of protein-free DNA. However, no significant differences were detected in the replication efficiencies between proteinfree DNA in the absence or presence of DEK (Fig. 5, DNA).

Taken together, these data reveal that DEK specifically interacts with chromatin, alters the topology of nucleosomal DNA, and reduces the efficiency with 
$\mathbf{A}$
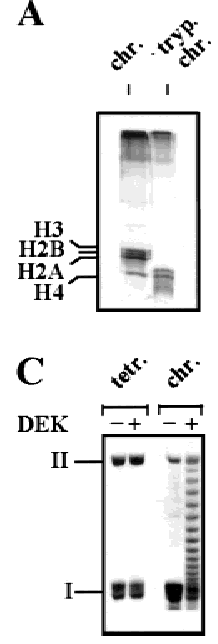

B
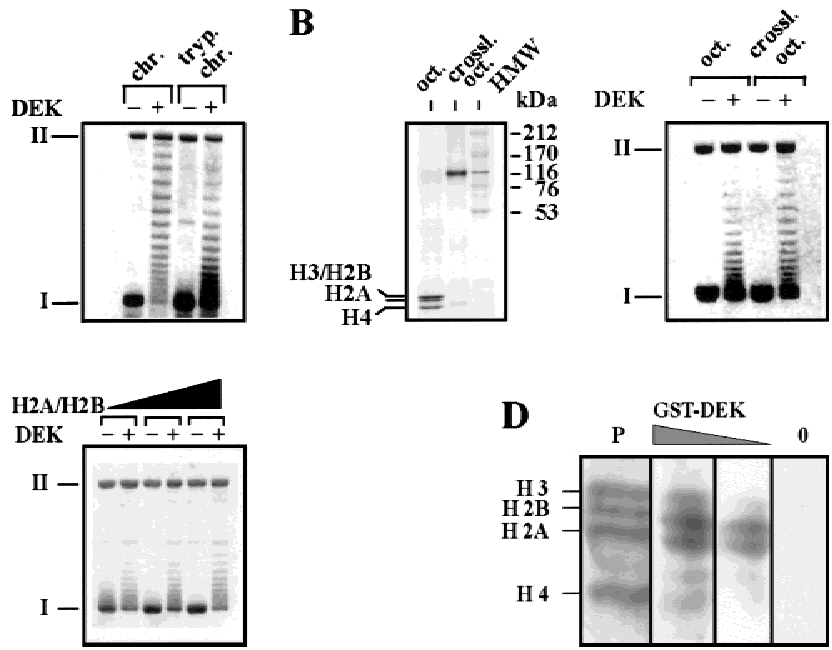

Figure 4. The DEK-induced change in topology depends on the presence of $\mathrm{H} 2 \mathrm{~A} / \mathrm{H} 2 \mathrm{~B}$ dimers. $(A$, left $)$ The amino-terminal histone domains of SV40 minichromosomes were removed by trypsin. Polypeptides were investigated by SDS-PAGE and visualized by silver staining. (Right) Non-treated chromatin (chr.) and trypsinized chromatin (tryp. chrom.) was used as substrate in the DEK assay. (B, left) Histone octamers (oct.) were cross-linked with DMS (crossl. oct.) and analyzed by SDS-PAGE stained with Coomassie brilliant blue. (HMW) High molecular weight marker in kilodaltons. (Right) SV40 DNA was reconstituted with control or cross-linked octamers and used as substrate in the DEK assay. $(C$, left $)$ SV40 DNA was reconstituted with purified $\mathrm{H} 3 / \mathrm{H} 4$ tetramers (tetr.) or histone octamers (chrom.). Chromatin was incubated in the absence or presence of DEK. (Right) H3/H4 containing chromatin was reconstituted with increasing amounts of $\mathrm{H} 2 \mathrm{~A} / \mathrm{H} 2 \mathrm{~B}$ dimers and used as substrate in the DEK assay. $(D)$ Far-Western blot analysis. Core histones were separated on an SDS-polyacrylamide gel, electroblotted, and renatured. The membrane was stained with Ponceau red $(\mathrm{P})$ and incubated with decreasing amounts of GST-DEK $\left(100 \mathrm{ng} / \mathrm{cm}^{2} ; 25 \mathrm{ng} / \mathrm{cm}^{2}\right)$ and without DEK (0). The position of the core histones are indicated.

which chromatin is replicated. Thus, DEK protein may have a global role in the structure and activity of chromatin. It is an interesting question whether the DEKCAN fusion protein, expressed in AML (von Lindern et
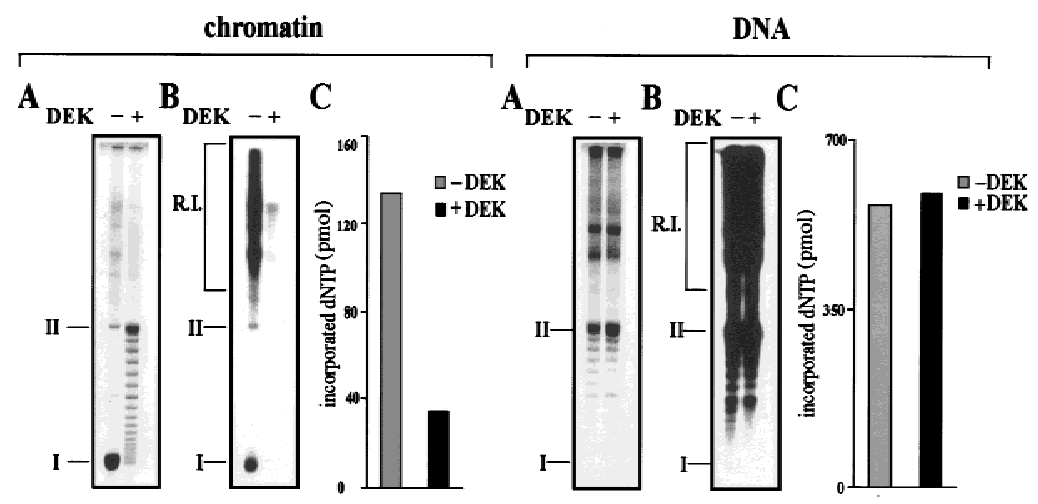

\section{DNA}

Figure 5. DEK inhibits the replication of chromatin but not of protein-free DNA. (A) SV40 DNA and SV40 chromatin were preincubated with DEK and topoisomerase I and used as templates in the SV40 in vitro replication system. Purified DNA was separated on an agarose gel and visualized by ethidium bromide staining. (B) Autoradiography of the agarose gel shown in $A$. The position of replicative intermediates (R.I.) of supercoiled (I) and relaxed closed circular and nicked molecules (II) are indicated. (C) Nucleotide incorporation (pmole) of the samples shown in $B$, as determined by TCA precipitation. al. 1992), is also able to perform these changes and whether these effects contribute to the transforming potential of the protein.

\section{Materials and methods}

Purification of DEK

HeLa cells $\left(1.5 \times 10^{10}\right.$; Computer Cell Culture Center, SA, Belgium) were resuspended in hypotonic buffer (20 mM HEPES-KOH at pH 7.4, $5 \mathrm{~mm} \mathrm{KCl}, 1.5$ $\mathrm{mm} \mathrm{MgCl}_{2}, 0.1 \mathrm{~mm}$ DTT) and homogenized in a Dounce homogenizer. Nuclei were pelleted for 10 min at $9000 \mathrm{rpm}$ (SS34) at $4^{\circ} \mathrm{C}$. Nuclear proteins were eluted for 45 min with 2 volumes of buffer A-300 (20 m M HEPES at pH 7.6, $300 \mathrm{~mm} \mathrm{NaCl}, 10$ mM sodium bisulfite, 1 mм EDTA) and centrifuged for $30 \mathrm{~min}$ at $9000 \mathrm{rpm}$ (SS34) at $4^{\circ} \mathrm{C}$. The supernatant was adjusted to $100 \mathrm{~mm} \mathrm{NaCl}, 10 \%$ glycerol, 10 mм $\beta$-mercaptoethanol, and supplied with a protease inhibitor cocktail (Boehringer Mannheim) and stirred for $15 \mathrm{~min}$ on ice.

About $200 \mathrm{ml}$ of nuclear extract were purified according to the flow chart outlined in Figure 1A. All columns were pre-equilibrated with buffer A-100 and eluted with the indicated salt steps. For purification, we used the following columns: a 20-ml CM Sepharose column (Pharmacia), a 3-ml Q Sepharose column (Pharmacia), a 1.2-ml DEAE-Sepharose column (Pharmacia), a 0.4-ml POROS/HQ column (Boehringer Mannheim), and a 0.5-ml heparinSepharose column (Pharmacia). Columns were eluted with the indicated salt steps with the following total volumes: $140,30,14.4,6$, and $10 \mathrm{ml}$, respectively. Finally, DEK-containing fractions were loaded onto a 0.8 -ml POROS-HQ/F column (Boehringer Mannheim), washed with 5 volumes of buffer A-100, and eluted with a 12-ml linear gradient. From $1.5 \times 10^{10} \mathrm{HeLa}$ cells, $\sim 20 \mu \mathrm{g}$ of DEK protein could be purified to near homogeneity.
DEK assay (reduction of the superhelical density of chromatin)

A total of $4 \mu \mathrm{l}$ of the fractions ( 100 ng of DEK protein) were dialyzed on a Whatman Filter (Type VS, pore size $0.025 \mu \mathrm{m}$ ) against buffer A-100 in the presence of $1 \mu \mathrm{g} / \mu \mathrm{l} \mathrm{BSA} \mathrm{(Pharmacia)} \mathrm{for} 90 \mathrm{~min}$ at $4^{\circ} \mathrm{C}$ and $100-\mathrm{ng}$ salt-treated SV40 minichromosomes (Gruss and Knippers 1995) were incubated with the dialyzed fraction in the presence of 5 units of topoisomerase I (Promega) and 200 $\mathrm{ng} / \mathrm{\mu l} \mathrm{BSA}$ in $20 \mathrm{~mm}$ HEPES at pH 7.6, $120 \mathrm{~mm} \mathrm{NaCl}, 1 \mathrm{~mm}$ EDTA, and $10 \mathrm{~mm}$ sodiumbisulfite for $30 \mathrm{~min}$ at $37^{\circ} \mathrm{C}$. Purified DNA was separated on an $0.8 \%$ agarose gel in $0.5 \times$ TBE-buffer at $3.5 \mathrm{~V} / \mathrm{cm}$ for $16 \mathrm{hr}$.

Sedimentation analysis

Salt-treated SV40 minichromosomes ( $8 \mu \mathrm{g})$ were incubated in the presence or absence of $8 \mu \mathrm{g}$ of DEK with 30 units of topoisomerase I for $1 \mathrm{hr}$ at $37^{\circ} \mathrm{C}$ in buffer A100/0.2 $\mu \mathrm{g} / \mathrm{\mu l}$ BSA. Complexes were loaded on $4-\mathrm{ml} 10 \%-35 \%$ glycerol gradients (20 mM HEPES at $\mathrm{pH} 7.6,10 \mathrm{~mm}$ sodium disulfite, $1 \mathrm{~mm}$ EDTA, $100 \mathrm{~mm} \mathrm{NaCl}$ ) and run in a TLS55 rotor for $1 \mathrm{hr}$ at 55,000 $\mathrm{rpm}$ at $4^{\circ} \mathrm{C}$. TCA-precipitated proteins were separated on an $18 \%$ SDS-polyacrylamide gel and stained with silver. DNA was investigated by $0.8 \%$ agarose gel electrophoresis. In the absence of chromatin, the DEK protein was found in fractions 1-3 (not shown).

Far-Western blot analysis

Core histones $(5 \mu \mathrm{g})$ were separated on an $18 \%$ SDS-PAGE and electroblotted to polyvinylidene difluoride membranes (Immobilon-P; Millipore). After transfer, the blots were stained with Ponceau red, and the positions of the four core histones were marked. Renaturation of the core 
histones was done in PBS-0.05\% Tween 20 (PBST) for $2 \mathrm{hr}$ at room temperature, and the membrane was blocked in PBS-BSA (PBS, $2 \%$ BSA, $0.5 \% \mathrm{NP} 40$ ) for $2 \mathrm{hr}$ at room temperature. The membrane was incubated with recombinant GST-DEK protein $\left(250-100 \mathrm{ng} / \mathrm{cm}^{2}\right.$ filter) in PBS-BSA for $2 \mathrm{hr}$ at room temperature, and DEK binding was detected by antibody staining with ECL (Amersham).

\section{In vitro replication assay}

The experiments were carried out as described previously (Gruss et al. 1993) using purified SV40 T-Ag as initiator protein and cytosolic HeLa S100 extract as source for replication enzymes. For in vitro replication, $400 \mathrm{ng}$ of salt-treated SV40 minichromosomes and $100 \mathrm{ng}$ of SV40 DNA were preincubated with $400 \mathrm{ng}$ of DEK, $3 \mathrm{~mm}$ ATP, and $2 \mu \mathrm{g}$ of T-Ag for $30 \mathrm{~min}$ at $37^{\circ} \mathrm{C}$, and then used as templates exactly as described (Alexiadis et al. 1998). Purified replication products were run on an $0.8 \%$ agarose gel in TBE buffer $(14 \mathrm{hr}, 3.5 \mathrm{~V} / \mathrm{cm})$. One-tenth of the replication assay was precipitated with TCA to determine the incorporated nucleotides.

\section{Acknowledgments}

We thank R. Mettke for technical assistance, B. Vestner for cross-linked histone octamers, Wen Jiang for purified NAP1 protein, and G. Grosveld for DEK expression vectors. We are very grateful to Jim Kadonaga for critical comments on the manuscript. This work was supported by grants from DFG to C.G. Work in the Protein Interaction Laboratory is supported by the Danish National Research Foundation.

The publication costs of this article were defrayed in part by payment of page charges. This article must therefore be hereby marked "advertisement" in accordance with 18 USC section 1734 solely to indicate this fact.

\section{References}

Alexiadis, V., L. Halmer, and C. Gruss. 1997. Influence of core histone acetylation on SV40 minichromosomes replication in vitro. Chromosoma 105: 324-331.

Alexiadis, V., P.D. Varga-Weisz, E. Bonte, P.B. Becker, and C. Gruss. 1998. In vitro chromatin remodelling by CHRAC at the SV40 origin of DNA replication. EMBO J. 17: 3428-3438.

Ausio, J., F. Dong, and K.E. van Holde. 1989. Use of selectively trysinized nucleosome core particles to analyze the role of the histone "tails" in the stabilization of the nucleosome. J. Mol. Biol. 206: 451-463.

Cairns, B.R., Y. Lorch, Y. Li, M. Zhang, L. Lacomis, H. Erdjument-Bromage, P. Tempst, J. Du, B. Laurent, and R.D. Kornberg. 1996. RSC, an essential, abundant chromatin-remodeling complex. Cell 87: 12491260.

Chang, L., S.S. Loranger, C. Mizzen, S.G. Ernst, C.D. Allis, and A.T. Annunziato. 1997. Histones in transit: Cytosolic histone complexes and diacetylation of $\mathrm{H} 4$ during nucleosome assembly in human cells. Biochemistry 36: 469-480.

Felsenfeld, G. 1996. Chromatin unfolds. Cell 86: 16-19.

Fu, G.K., G. Grosveld, and D.M. Markovitz. 1997. DEK, an autoantigen involved in a chromosomal translocation in acute myelogenous leukemia, binds to the HIV-2 enhancer. Proc. Nat1. Acad. Sci. 94: 18111815.

Grunstein, M. 1997. Histone acetylation in chromatin structure and transcription. Nature 389: 349-352.

- 1998. Yeast heterochromatin: Regulation of its assembly and inheritance by histones. Cell 93: 325-328.

Gruss, C. and R. Knippers. 1995. The SV40 minichromosome. In Methods in molecular genetics (ed. K.W. Adolph), pp. 101-113. Academic Press, Orlando, FL.

Gruss, C., J. Wu, T. Koller, and J.M. Sogo. 1993. Disruption of the nucleosomes at the replication fork. EMBO J. 12: 4533-4545.

Halmer, L. and C. Gruss. 1997. Accessibility for topoisomerase I and II regulates the replication efficiency of SV40 minichromosomes in vitro. Mol. Cell. Biol. 17: 2624-2630.

Halmer, L., B. Vestner, and C. Gruss. 1998. Involvement of topoisomerases in the initiation of simian virus 40 minichromosome replication. J. Biol. Chem. 274: 34792-34798.

Ito, T., M. Bulger, M.J. Pazin, R. Kobayashi, and J.T. Kadonaga. 1997. ACF, an ISWI-containing and ATP-utilizing chromatin assembly and remodeling factor. Cell 90: 145-155.

Kingston, R.E., C.A. Bunker, and A.N. Imbalzano. 1996. Repression and activation by multiprotein complexes that alter chromatin structure. Genes \& Dev. 10: 905-920.

Kornberg, R.D. and Y. Lorch. 1999. Chromatin-modifying and remodeling complexes. Curr. Opin. Genet. Dev. 9: 148-151.

Krude, T. and R. Knippers. 1991. Transfer of nucleosomes from parental to replicated chromatin. Mol. Cell. Biol. 11: 6257-6267.

LeRoy, G., G. Orphanides, W.S. Lane, and D. Reinberg. 1998. Requirement of RSF and FACT for transcription of chromatin templates in vitro. Science 282: 1900-1904.

Luger, K., A.W. Mäder, R.K. Richmond, D.F. Sargent, and T.J. Richmond. 1997. Crystal structure of the nucleosome core particle at 2.8 A resolution. Nature 389: 251-260.

Ogbourne, S. and T.M. Antalis. 1998. Transcriptional control and the role of silencers in transcriptional regulation in eukaryotes. Biochem. J. 331: $1-14$.

Peterson, C.L. 1996. Multiple switches to turn on chromatin. Curr. Biol. 6: $171-175$.

Peterson, C.L. and J.W. Tamkum. 1995. The SWI-SNF complex: A chromatin remodeling machine? Trends Biochem. Sci. 20: 143-146.

Pirrotta, V. 1997. PcG complexes and chromatin silencing. Curr. Opin. Genet. Dev. 7: 249-258.

- 1998. Polycombing the genome: PcG, trxG, and chromatin silencing. Cell 93: 333-336.

Quintini, G., K. Treuner, C. Gruss, and R. Knippers. 1996. Role of aminoterminal histone domains in chromatin replication. Mol. Cell. Biol. 16: $2888-2897$.

Struhl, K. 1998. Histone acetylation and transcriptional regulatory mechanisms. Genes \& Dev. 12: 599-606.

Svaren, J. and W. Hürz. 1996. Regulation of gene expression by nucleosomes. Curr. Opin. Genet. Dev. 6: 164-170.

Thomas, J.O. 1989. Chemical cross-linking of histones. Methods Enzymol. 170: 549-563.

Tong, J.K., C.A. Hassig, G.R. Schnitzler, R.E. Kingston, and S.L. Schreiber. 1998. Chromatin deacetylation by an ATP-dependent nucleosome remodelling complex. Nature 395: 917-921.

Tsukiyama, T. and C. Wu. 1995. Purification and properties of an ATPdependent nucleosome remodeling factor. Cell 83: 1011-1020.

Varga-Weisz, P.D., M. Wilm, E. Bonte, K. Dumas, M. Mann, and P.B. Becker. 1997. Chromatin-remodelling factor CHRAC contains the ATPases ISWI and topoisomerase II. Nature 388: 598-602.

Vestner, B., M. Bustin, and C. Gruss. 1998. Stimulation of replication efficiency of a chromatin template by chromosomal protein HMG17. J. Biol. Chem. 273: 9409-9414.

von Lindern, M., M. Fornerod, S. van Baal, M. Jaegle, T. de Wit, A. Buijs, and G. Grosveld. 1992. The translocation $(6 ; 9)$, associated with a specific subtype of acute myeloid leukemia, results in the fusion of two genes, dek and can, and the expression of a chimeric, leukemiaspecific dek-can mRNA. Mol. Cell. Biol. 12: 1687-1697.

Wallrath, L.L. 1998. Unfolding the mysteries of heterochromatin. Curr. Opin. Genet. Dev. 8: 147-153.

Wang, W., J. Coté, Y. Xue, S. Zhou, P.A. Khavari, S.R. Biggar, C. Muchardt, G.V. Kalpana, S.P. Goff, M. Yaniv et al. 1996. Purification and biochemical heterogeneity of the mammalian SWI-SNF complex. EMBO I. 15: 5370-5382.

Wilm, M., A. Shevchenko, T. Houthaeve, S. Breit, L. Schweigerer, T. Fotsis, and M. Mann. 1996. Femtomole sequencing of proteins from polyacrylamide gels by nano electrospray mass spectrometry. Nature 379: 466-469.

Xue, Y., J. Wong, G.T. Moreno, M.K. Young, J. Cote, and W. Wang. 1998. NURD, a novel complex with both ATP-dependent chromatin-remodeling and histone deacetylase activities. Mol. Cell 2: 851-861.

Zucker, K. and A. Worcel. 1990. The histone H3/H4 N1 complex supplemented with histone H2A-H2B dimers and DNA topoisomerase I forms nucleosomes on circular DNA under physiological conditions. J. Biol. Chem. 266: 14487-14496. 


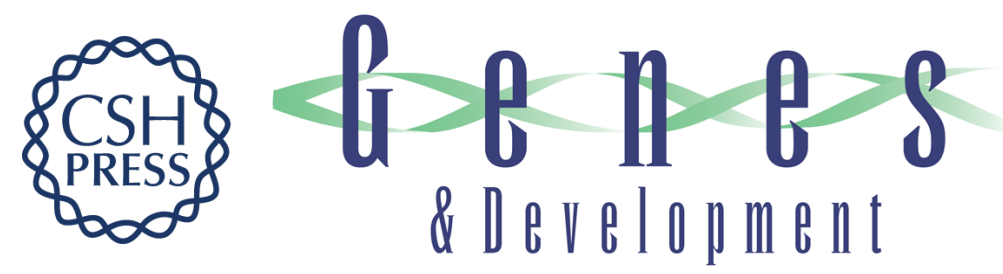

\section{The protein encoded by the proto-oncogene DEK changes the topology of chromatin and reduces the efficiency of DNA replication in a chromatin-specific manner}

Vassilios Alexiadis, Tanja Waldmann, Jens Andersen, et al.

Genes Dev. 2000, 14:

Access the most recent version at doi:10.1101/gad.14.11.1308

\section{References This article cites 35 articles, 10 of which can be accessed free at: http://genesdev.cshlp.org/content/14/11/1308.full.html\#ref-list-1}

License

Email Alerting Service

Receive free email alerts when new articles cite this article - sign up in the box at the top right corner of the article or click here.

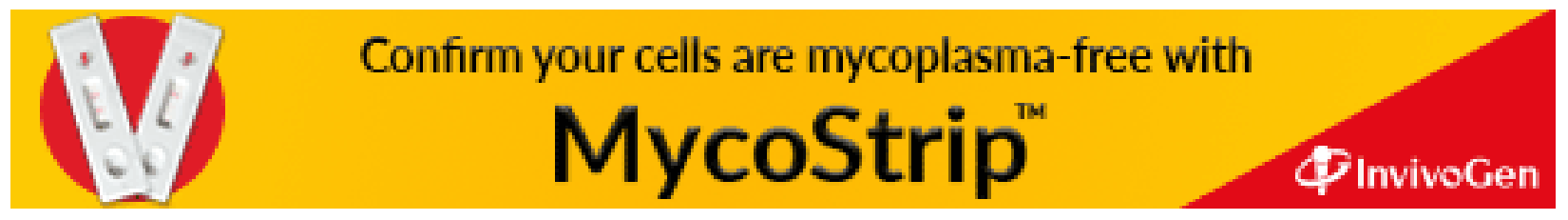

